\title{
COMUNICAÇÃO
}

\section{EVIDÊNCIAS SOROLÓGICAS DA CIRCULAÇÃO DO ARBOVÍRUS ROCIO (FLAVIVIRIDAE) NA BAHIA}

\author{
Andréa Straatmann, Sandro Santos-Torres, Pedro F.C. Vasconcelos, \\ Amélia P.A. Travassos da Rosa, Sueli G. Rodrigues e José Tavares-Neto
}

\begin{abstract}
Oito casos com anticorpos anti-Rocio são descritos, de quatro cidades do Estado da Babia, sendo seis portadores de anticorpos IgG (IH e TN) e dois IgM (ELISA e TN). Os autores comentam sobre a circulação deste arbovírus no Estado, e as possibilidades de reações cruzadas com outros vírus antigenicamente relacionados.
\end{abstract}

Palavras-chaves: Rocio. Arbovírus. Falvivírus. Babia.

Entre 1975-1977, grave epidemia de encefalite ocorreu nos municípios Peruíbe, Itanhaém, Mongagua, localizados no Vale do Ribeira, litoral do Estado de São Paulo24. A análise retrospectiva sugeriu, no entanto, que o início da epidemia teria ocorrido provavelmente entre 1973-19747. Casos esporádicos sugestivos (IgM positiva) da doença foram notificados até 1989, nesta região de São Paulo8 10. Um total de 1021 casos foram diagnosticados no Estado de São Paulo no período de 1975-1977; a epidemia de 1975 ocorreu na Baixada Santista, enquanto a de 1976-1977 ocorreu quase exclusivamente no vale do Ribeira; nesta última região, a incidência de encefalite por 100.000 habitantes para os anos de 1975, 1976, e 1977, respectivamente, foram de 147,6; 201,4 ; e 46,7. A letalidade foi de $10 \%$ e a incidência de seqüelas definitivas ficou em torno de $20 \%$ dos casos 925 . No mesmo período, cinco casos de encefalite foram também descritos na região nordeste do Estado do Paraná, em área limítrofe da região afetada no Estado de São Paulo12 21.

Durante a epidemia, Lopes e col14 isolaram amostras de um novo flavivírus, posteriormente chamado Rocio, de cerebelo e medula cervical de nove casos fatais, de um camundongo sentinela e de uma ave silvestre Zenothrichia capensis - estudos sorológicos sugerem a participação de aves silvestres no ciclo de

Faculdade de Medicina da Universidade Federal da Bahia, Salvador, BA; Instituto Evandro Chagas/FNS-MS, Belém, PA. Financiado pelo CNPq, CAPES (PET-Medicina) e FNS/IEC.

Endereço para correspondência: Prof. José Tavares-Neto. Dept $^{\circ}$ de Medicina, Faculdade de Medicina, Campus UFBA/Canela, 40110-160 Salvador, BA.

Recebido para publicação em 03/01/97. transmissão do Rocio 2 . No entanto, em sangue de seres humanos, o isolamento viral não foi conseguido de 367 pacientes com manifestações clínicas, nos primeiros cinco dias de doença13 14. De uma das áreas epidêmicas, 38.896 mosquitos pertencentes a 88 espécies foram coletados por isca humana e isca luminosa; de um lote de 19 mosquitos Psorophora ferox o vírus Rocio foi isolado15. Por outro lado, a suscetibilidade do mosquito Aedes scapularis à infecção oral com o vírus Rocio, sua habilidade de transmitir o vírus experimentalmente, e sua abundância e estreita associação com o homem na zona epidêmica, faz dessa espécie suspeita como vetor durante as epidemias de 1975-1976456.

Em testes sorológicos (IH, N e FC), o vírus Rocio apresenta relacionamento antigênico com outros flavivírus especialmente com os seguintes vírus: Ilhéus, Saint Louis (SLE), encefalite japonesa (JE) e encefalite do Murray Valley (MVE)11 16. Por "Western blot", o Rocio apresentou maior relacionamento antigênico com O MVE18.

Em 1985, Figueiredo3 descreveu um caso de moradora da região de Ribeirão Preto (noroeste do Estado de São Paulo) com anticorpos neutralizantes para Rocio, com sorologia negativa para os outros flavivírus circulantes no Brasil, e sem relato de residência ou viagens para o litoral do Estado de São Paulo. No ano seguinte, em uma $(0,3 \%)$ menina de 12 anos de idade foram detectados anticorpos IH e N do Rocio, entre os 288 habitantes do povoado de Corte de Pedra, município de Valença-Bahia, região Litoral Sul23 - sem história de viagens anteriores para outra região do Estado da Bahia ou do País e quadro clínico, recente ou passado, compatível com doença neurológica. 
Comunicação. Straatmann A, Santos-Torres S, Vasconcelos PFC, Rosa APAT, Rodrigues SG, Tavares-Neto J. Evidências sorológicas da circulação do arbovírus Rocio (Flaviviridae) na Babia. Revista da Sociedade Brasileira de Medicina Tropical 30:511-515, nov-dez, 1997.

O perfil sorológico desta criança baiana não apresentava anticorpos para os outros 18 arbovírus de importância médica no Brasil testados, das famílias Togaviridae, Flaviviridae ou Bunyaviridae, bem como os pais e três irmãos não apresentavam anticorpos antiRocio ou para os outros arbovírus testados 23 .

Mais recentemente, em maio de 1995 , durante a epidemia de dengue- 2 na cidade de Salvador, três casos investigados inicialmente suspeitos dessa virose apresentaram anticorpos IgM (MAC-ELISA) para o vírus Rocio 22. A segunda amostra sérica, colhida 20 dias após, confirmou a presença de anticorpos $\mathrm{N}$ em dois daqueles casos (ILN > 2,6 e 2,8), sendo soro-negativos em testes IH para os seguintes vírus: Bussuquara, Dengue 1-4, Febre amarela (amostra silvestre BEH111, e vacinal 17D), Ilheus, St. Louis, e outros 10 arbovírus das famílias assinaladas acima. Todos os outros co-habitantes $(n=18)$, dos dois casos com IgM positiva para Rocio, foram negativos por IH para os 19 arbovírus testados, inclusive o Rocio. Os dois pacientes (homem/23 anos e mulher/31 anos) apresentaram cefaléia prolongada, de 13 a 15 dias, respectivamente. Os dois indivíduos residiam no bairro de Brotas, em Salvador, em domicílios separados cerca de 500 metros, existindo entre eles um vale com córrego de água natural, arborizado com mata nativa. O terceiro caso (mulher/52 anos; IgM-positiva anti-Rocio) residia aproximadamente $2 \mathrm{~km}$, dos outros dois casos, no bairro de São Caetano. Os três pacientes negavam viagem ou outro deslocamento para fora da cidade do Salvador nos últimos seis meses - um deles, porém, tinha ocupação indefinida (homem/23 anos) e sendo foragido da Justiça, mudava freqüentemente de endereço. As duas outras pacientes eram donas de casa, de famílias de nível sócio-econômico baixo.

De 22 a 30 de julho e 18 a 22 de dezembro de 1995, respectivamente, nas localidades de Ipupiara e Prado, Estado da Bahia, foi realizado inquérito soro-epidemiológico para arboviroses. A cidade de Ipupiara fica localizada na região da Chapada Diamantina e a de Prado no litoral da região Sul da Bahia. Na cidade de Ipupiara, foram coletados soros dos moradores em uma de cada 10 casas, das quadras da cidade; na cidade do Prado coletou-se soro de uma em cada 25 residências, também conforme a numeração das casas/quadras da Fundação Nacional da Saúde (FNS). Deste modo, na cidade de Ipupiara foram coletadas 461 amostras e na cidade do Prado 228 amostras.

As amostras sorológicas foram testadas no Laboratório de Arbovírus, do Instituto Evandro Chagas/FNS-Belém, utilizando o teste de IH, usando a microtécnica descrita por Shope19, com os antígenos dos seguintes arbovírus: gênero Flavivirus (Dengue 1-4, Febre amarela silvestre, Febre amarela vacinal/17D, Ilheus, Rocio e St. Louis), Togavirus (encefalite equina leste, encefalite equina oeste, Mayaro e Mucambo), e Bunyavirus (Caraparu, Guaroa, Catu, Maguari, Oropouche, e Tacaiuma). Os soros com anticorpos IH foram testados por N, utilizando-se a técnica de diluição constante do soro (1:8), com diluições seriadas de 10 vezes do vírus investigado. O inóculo foi realizado em camundongos swiss 1 . Os casos com índice logarítmico de neutralização $\geq 1,7$ foram considerados com anticorpos $\mathrm{N}$ positivos 20 .

Nos 689 soros testados cinco $(0,7 \%)$ apresentaram anticorpos (IH e N) para Rocio, sendo em 0,6\% (3/461) habitantes da cidade de Ipupiara e 0,9\% (2/228) de Prado. Dos cinco soros com anticorpos (IgG) do Rocio, três $(0,7 \%)$ eram do sexo feminino $(3 / 421)$ e dois $(0,8 \%)$ do masculino $(2 / 268)$, com idades de 13 a 72 anos e média de 46,6 $\pm 21,4$ anos (quatro casos tinham idades $\geq 45$ anos), sendo que nos soro-negativos a variação foi de 9 a 75 anos e média de 40,0 $\pm 20,7$ anos. A criança de 13 anos era do sexo masculino, e residia em Ipupiara. Somente um caso soro-reagente de Rocio, da cidade de Ipupiara, referia residência anterior no Estado de Goiás - inclusive este caso, todos negavam residências ou deslocamentos para outros Estados do Brasil. Nenhum indivíduo tinha história de quadro semelhante a encefalite nem apresentavam seqüelas.

Nenhum dos casos Rocio-positivos (IH e N), das cidades de Prado e Ipupiara, relatou história de vacinação para a febre amarela (17D) e, nem possuíam anticorpos vacinais (anti-17D) por IH. Os três casos de Ipupiara não tinham anticorpos IH para os 18 outros arbovírus testados. Porém, os indivíduos de Prado tinham anticorpos $\mathrm{N}$ para Ilheus (ILN > 2,3 e $\geq 3,3$ ), e um deles também para Dengue 2 - nestes dois casos os ILN do Rocio foram, respectivamente, $=2,5$ e $=3,0$.

Não se pode afastar a hipótese que estes casos com anticorpos $\mathrm{N}$ para Rocio, inclusive os anteriormente descritos 22 23, não sejam 
Comunicação. Straatmann A, Santos-Torres S, Vasconcelos PFC, Rosa APAT, Rodrigues SG, Tavares-Neto J. Evidências sorológicas da circulação do arbovírus Rocio (Flaviviridae) na Babia. Revista da Sociedade Brasileira de Medicina Tropical 30:511-515, nov-dez, 1997.

devidos à infecção para outro flavivírus antigenicamente relacionado ao Rocio. Porém, exceto os dois casos da cidade de Prado, os demais casos $(n=6)$ do Estado da Bahia, não apresentavam anticorpos para os outros arbovírus testados.

Os dois casos da cidade de Prado com anticorpos para Ilheus e Rocio, não parecem ser decorrentes de reação cruzada entre eles, mas respostas monotípicas independentes, ou seja, infecções em diferentes períodos. No Vale do Ribeira, Estado de São Paulo, o mesmo tipo de co-infecção foi também observada. Provavelmente porque o ciclo epidemiológico do Ilheus que é bem estabelecido parece ter semelhanças com o do Rocio, ainda não completamente elucidado, envolvendo aves silvestres e culicídeos, como o mosquito P. ferox 1117 .

$\mathrm{Na}$ população dos municípios do Vale do Ribeira-São Paulo, durante o período de maior incidência da epidemia de encefalite pelo Rocio, a freqüência de casos com infecção assintomática deve ter sido significativa 7 . Portanto, os casos descritos no Estado da Bahia, se afastada a possibilidade de reação cruzada com outro vírus antigenicamente relacionado, podem também representar formas assintomáticas da infecção pelo Rocio.

Os dois casos descritos, procedentes da cidade do Salvador, e sintomáticos, com cefaléia de duração prolongada, podem representar casos oligossintomáticos ou subclínicos da infecção. Apesar da freqüência destes casos ser desconhecida7 9 . Deve ser ressaltado no entanto que no período de ocorrência destes casos em Salvador, ou subseqüentemente, não foi observado o aumento do número de casos de encefalite ou da síndrome de meningite asséptica nas unidades de vigilância da cidade do Salvador, especialmente no Hospital Couto Maia (J Pereira-Dias: informação pessoal, 1996).

O povoado de Corte de Pedra/Valença (cidade litorânea) tem clima tropical úmido, como também a cidade de Prado, que é litorânea. Ambos os municípios têm restos de Mata Atlântica, outra semelhança com os municípios do Vale do Ribeira, SP. Surpreende que os dois casos da capital do Estado, também de clima tropical úmido, residiam em bairro onde há próximo o Horto Florestal de Salvador e as residências eram limítrofes de vale com características nativas, razoavelmente preservadas. Diferentemente, são as características fisiográficas do município de Ipupiara, localizado na região central do Estado, que apresenta vegetação de campo cerrado, em grande parte ocupado por pastagens, e clima tropical seco. Também, as características demográficas, culturais e sócioeconômicas destas localidades baianas são bastante diferentes das assinaladas no Vale do Ribeira, especialmente às da cidade de Ipupiara.

Em conclusão, as evidências sorológicas de circulação do vírus Rocio no Estado da Bahia devem deixar as unidades de vigilância epidemiológicas alertas, para a possibilidade da circulação deste vírus. Deve ser lembrado que durante a epidemia de encefalite pelo Rocio, no Vale do Ribeira, SP, observou-se que a maioria da população local não tinha imunidade prévia contra o vírus, desconhecido até então, e a busca retrospectiva de casos7 detectou pacientes portadores de seqüelas compatíveis com a doença prévia pelo Rocio, ocorrida dois a três anos antes do período de incidência maior da epidemia.

Até o presente, nenhum caso de encefalite pelo Rocio foi relatado fora da área epidêmica.

Estes achados sorológicos devem ser interpretados com cautela em vista de possíveis reações antigênicas cruzadas com outros flavivírus, e sugerem a necessidade de investigações prospectivas no futuro.

\section{SUMMARY}

Eight antibody anti-Rocio cases, from four distinct cities in the state of Babia, are described; six of them being carriers of the antibody $\operatorname{IgG}$ (HI and NT) and two IgM (ELISA and NT). The authors comment on the circulation of these arboviruses in the state of Babia and on the possibility of cross reactions with other antigenically related viruses.

Key-words: Rocio. Arbovirus. Flavivirus. Babia.

\section{AGRADECIMENTOS}

Aos funcionários da FNS de Ipupiara e Prado pelo fornecimento dos mapas das cidades e diversas outras colaborações; as Pósgraduandas Dras. Ana Emília Torres-Morales (UNICAMP) e Karla Mota (UFBA) por terem colaborado na coleta das amostras séricas e levantamento dos dados de Ipupiara; e, especialmente, o técnico Zoroastro Terra Teixeira, do Hospital Couto Maia, pelo auxílio nas coletas das amostras séricas de Ipupiara e Prado e aos técnicos do Laboratório de Arbovírus do IEC-Belém. 


\section{REFERÊNCIAS BIBLIOGRÁFICAS}

1. Casals J. Immunological techniques for animal viruses. In: Moramorosh K, Koprowski H (eds), Methods in Virology. Academic Press, New York, v.3, p. 175-181, 1967.

2. Ferreira IB, Pereira LE, Rocco IM, Marti AT, Souza LT, Iversson LB. Surveillance of arbovirus infections in the Atlantic Forest Region, State of São Paulo, Brazil. I. Detection of hemagglutination-inihibiting antibodies in wild birds between 1978 and 1990. Revista do Instituto de Medicina Tropical de São Paulo 36: 265-274, 1994.

3. Figueiredo LTM. Estudo sobre infecções por arbovírus na região de Ribeirão Preto, Estado de São Paulo. Tese de doutorado, Faculdade de Medicina de Ribeirão Preto da Universidade de São Paulo, Ribeirão Preto, SP, 1985.

4. Forattini OP, Gomes AC, Natal D, Kakitiani I, Mararucci D. Preferências alimentares de mosquitos Culicidae no Vale do Ribeira. São Paulo, Brasil. Revista de Saúde pública 21: 171187, 1987a.

5. Forattini OP, Gomes AC, Natal D, Kakitiani I, Mararucci D. Freqüência domiciliar e endofilia de mosquitos Culicidae no Vale do Ribeira, São Paulo, Brasil. Revista de Saúde pública 21:288292, 1987b.

6. Forattini OP, Kakitani I, Massad E, Marucci D. Studies on mosquitoes (Diptera: Culicidae) and anthropic environment. Synanthropy and epidemiological vector role of Aedes scapularis in south-eastern Brazil. Revista de Saúde pública 29: 199-207, 1995.

7. Iversson LB. Aspectos da epidemia de encefalite por arbovírus na região do Vale do Ribeira, São Paulo, Brasil, no período de 1975 a 1978. Revista de Saúde Pública 14: 9-35, 1980.

8. Iversson LB, Coimbra TLM,Travassos da Rosa APA, Monath TP. Use of immunoglobulin M antibody capture enzyme-linked immunosorbent assay in the surveillance of Rocio encephalitis. In: $36^{\circ}$ Annual Meeting of American Society of Tropical Medicine and Hygiene, Los Angeles, p.267, 1987.

9. Iversson LB, Tiriba AC. Encefalite por arbovírus Rocio. In: Veronesi R, Focaccia R, Dietze R (eds) Doenças Infecciosas e Parasitárias. $8^{\mathrm{a}}$ edição, Guanabara Koogan, Rio de Janeiro, p. 166-173, 1991.

10. Iversson LB, Rosa APAT, Rosa MDB. Ocorrência recente de infecção humana por arbovírus Rocio na região do Vale do Ribeira. Revista do Instituto de Medicina Tropical de São Paulo 31: 28-31, 1989.

11. Karabatsos N. Internacional Catalogue of Arboviruses. Including certain other viruses of vertebrates. American Society of Tropical Medicine and Hygiene, $3^{\text {nd }}$ edition, San AntonioTexas, p. 1071-1076, 1985.

12. Kotaka PI, Baranski MC, Godoy OF, Silva AF, Szpeiter N, Silveira HB, Cunha CAM, Carvalho CR. Encefalite a vírus no litoral do Estado do Paraná. Relato de um caso internado no Hospital de Clínicas. In: Resumos do XIV Congresso da Sociedade Brasileira de Medicina Tropical, João Pessoa, p. 43, 1978.

13. Lopes OS. Rocio (ROC) strain: SPH: 34675. The American Journal Tropical Medicine and Hygiene 27: 418-419, 1979.

14. Lopes OS, Coimbra TLM, Sacchetta LA, Calisher $\mathrm{CH}$. Emergence of a new arbovirus disease in Brazil. II - Epidemiologic studies on 1975 epidemic. American Journal of Epidemiology 108: 394-401, 1978.

15. Lopes OS, Sacchetta LA, Francy DB, Jakob W, Calisher $\mathrm{CH}$. Emergence of a new arbovirus disease in Brazil. III - Isolation of Rocio virus from Psorophora ferox (Humboldt, 1819). American Journal of Epidemiology 113: 122-125, 1981.

16. Pinheiro FP, Leduc JW, Travassos da Rosa APA, Leite OF. Isolation of St. Louis encephalitis virus from blood of a patient in Belém, Brazil. The American Journal of Tropical Medicine and Hygiene 30: 145-148, 1981.

17. Pinheiro FP, Travassos da Rosa APA. Arboviroses. In: Veronesi $\mathrm{R}$, Focaccia $\mathrm{R}$, Dietze $\mathrm{R}$ (eds) Doenças Infecciosas e Parasitárias. $8^{\mathrm{a}}$ edição, Guanabara Koogan, Rio de Janeiro, p. 156-165, 1991.

18. Sakurai T, Bundo K, Igarashi H. Detection of Rocio virus-specific antigenic polypeptides in virusinfected cells and culture fluid by western blotting method. The American Journal of Tropical Medicine and Hygiene 27: 129, 1985.

19. Shope RE. The use of micro-hemagglutinationinihibition test to follow antibody response after arthropod-borne virus infection in a community of forest animals. Annals of Microbiology, XI part a: 167-171, 1963 .

20. Shope RE, Sather G.Arboviruses. In: Lennette EH, Smidt NJ (eds) Diagnostic procedures for viral, 
Comunicação. Straatmann A, Santos-Torres S, Vasconcelos PFC, Rosa APAT, Rodrigues SG, Tavares-Neto J. Evidências sorológicas da circulação do arbovírus Rocio (Flaviviridae) na Babia. Revista da Sociedade Brasileira de Medicina Tropical 30:511-515, nov-dez, 1997.

rickettsial and chlamydial infections. American Public Health Association, 5nd edition, Washington, 1979.

21. Szpeiter N. Encefalite por arbovírus do grupo B do litoral sul do Estado de São Paulo. Ocorrência de um caso autóctone altamente sugestivo dessa encefalite no litoral norte do Estado do Paraná. In: Resumos do XIII Congresso da Sociedade Brasileira de Medicina Tropical, Brasília, p. 19, 1977.

22. Tavares-Neto J, Rodrigues SG, Bastos C, TorresMorales AE, Travassos da Rosa A. Recent occurrence of human infection by Rocio arbivirus in Salvador, Bahia, Brazil. In: Resumos do XXXII Congresso da Sociedade Brasileira de Medicina Tropical, Goiânia, p. 78, 1996.
23. Tavares-Neto J, Travassos da Rosa APA, Vasconcelos PFC, Costa JML, Travassos da Rosa J, Marsden PD. Pesquisa de anticorpos para arbovírus no soro de residentes no Povoado de Corte de Pedra, Valença, Bahia. Memórias do Instituto Oswaldo Cruz 81: 351-358, 1986.

24. Tiriba AC. Epidemia de encefalite atribuída a arbovírus, ocorrida no litoral sul do estado de São Paulo em 1975: contribuição para o estudo clínico, São Paulo. Tese de Livre-Docência, Escola Paulista de Medicina, São Paulo, SP, 1975.

25. Tiriba AC, Miziara AM, Lourenço R, Costa CRB, Costa CS, Pinto GH. Encefalite humana primária epidêmica por arbovírus observada no litoral sul do Estado de São Paulo. Revista da Associação Médica Brasileira 22: 415-420, 1976. 